\title{
Arsenic accumulation and speciation in the submerged macrophyte Ceratophyllum demersum $\mathrm{L}$.
}

\author{
Peiying Xue • Changzhou Yan • Guoxin Sun • \\ Zhuanxi Luo
}

Received: 31 December 2011 / Accepted: 5 March 2012 /Published online: 21 March 2012

(C) Springer-Verlag 2012

\begin{abstract}
Introduction Ceratophyllum demersum L. is a widespread submerged macrophyte in aquatic environments.

Methods Simulation experiments were conducted in the laboratory to investigate arsenic (As) accumulation, speciation, and efflux of $C$. demersum exposed to arsenate and arsenite solutions.

Results Plant shoots showed a significant accumulation of

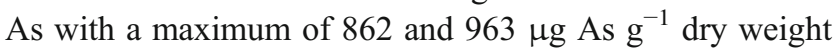
after 4 days of exposure to $10 \mu \mathrm{M}$ arsenate and arsenite, respectively. Regardless of whether arsenate or arsenite was supplied to the plants, arsenite was the predominant species in plant shoots. Furthermore, a dramatically higher influx rate of arsenate compared with arsenite was observed in $C$. demersum exposed to As solutions without the addition of phosphate (P). Arsenate uptake was considerably inhibited by $\mathrm{P}$ in this study, suggesting that arsenate is taken up by $C$. demersum via the phosphate transporters. However, arsenite uptake was unaffected by $\mathrm{P}$ and markedly reduced in the presence of glycerol and antimonite (Sb), indicating arsenite shares the aquaporin transport pathway. In addition, $C$. demersum rapidly reduces arsenate to arsenite in the shoot of the plant and extrudes most of them $(>60 \%)$ to the external solutions. The efflux of arsenite was much higher than that of
\end{abstract}

Responsible editor: Elena Maestri

P. Xue $\cdot$ C. Yan $(\bowtie) \cdot Z$. Luo

Key Laboratory of Urban Environment and Health, Institute of

Urban Environment, Chinese Academy of Sciences,

Xiamen 361021, China

e-mail: czyan@iue.ac.cn

G. Sun

Research Center for Eco-Environmental Sciences,

Chinese Academy of Sciences,

Beijing 100085, China arsenate; the former is supposed to be both active and passive processes, and the latter through passive leakage.

Conclusion C. demersum is a strong As accumulator and an interesting model plant to study As uptake and metabolism due to the lack of a root-to-shoot translocation barrier.

Keywords Arsenic · Arsenic speciation · Submerged macrophytes $\cdot$ Efflux $\cdot$ Uptake $\cdot$ As phytofiltration

\section{Introduction}

As one of the top carcinogens, inorganic As contamination of water resources poses a serious threat to the environment and human health in many countries of the world, especially in Bangladesh, West Bengal (India), Vietnam, and China, where millions of people are at risk of drinking As-contaminated water (Smedley and Kinniburgh 2002; Bhattacharjee 2007; Zhao et al. 2010). Additionally, people can also suffer from As toxicity through consumption of rice and vegetables irrigated with As-tainted water (Meharg and Hartley-Whitaker 2002; Tripathi et al. 2007; Zhu et al. 2008). Therefore, it is an urgent need to reduce As contamination in water. Phytoremediation has become a promising method for As removal in recent years because it is a cost-effective and eco-friendly way to remove pollutants (Srivastava et al. 2007; Zhu and Rosen 2009). Since the discovery of the brake fern's arsenic hyperaccumulation (Ma et al. 2001; Zhao et al. 2002), much study has been directed towards the accumulation, speciation, and metabolism of As in plants (Zhao et al. 2009).

Hyperaccumulation seems to have the following characteristics: enhanced arsenate uptake, decreased arsenite-thiol complexation and arsenite efflux to the external medium, markedly improved xylem translocation of arsenite, and arsenite sequestration in the vacuole of shoots (Zhao et al. 
2009). As for non-hyperaccumulating plants, several studies on terrestrial plants suggested that arsenate and arsenite enter plant cells via phosphate transporters and aquaglycerolporin channels, respectively (Abedin et al. 2002; Meharg and Hartley-Whitaker 2002; Meharg and Jardine 2003). In addition, the reduction of arsenate and complexation of arsenite by thiol peptides are considered to be important mechanisms of As detoxification (Srivastava et al. 2007; Zhao et al. 2009). Recent studies by Xu et al. (2007) and Zhang et al. $(2008,2009)$ also showed that rice and tomato roots as well as some species of duckweed rapidly reduce arsenate to arsenite and extrude arsenite to the external medium. However, little information is available on As accumulation and metabolism in submerged macrophytes. Studies on Azolla, Wolffia globosa, and the roots of rice and tomato suggest that $\mathrm{As}(\mathrm{V})$ in plant cells is rapidly reduced to As (III), followed by rapid efflux from the plant into external solutions (Xu et al. 2007; Zhang et al. 2008, 2009). If this is one of the detoxification mechanisms for As (V) in submerged macrophytes, the macrophytes themselves would become new sources of metal contamination to surrounding areas.

Since submerged macrophytes are completely inundated and have very thin cuticle, plant shoots may have the ability to directly take up metals from the surrounding water (Jackson 1998). In addition, due to their capacity for fast growth and high biomass production even under moderate nutritional conditions, it is possible that submerged macrophytes have tremendous potential to accumulate As from water. Hydrillia verticillata (L. f.) Royle and Ceratophyllum demersum are reported to be promising candidates for the phytofiltration of As-contaminated water owing to their higher tolerance of As than those normally occurring in contaminated areas and adequate As detoxification system, by stimulating antioxidant enzyme activity and augmenting the synthesis of thiols to overcome As phytotoxicity (Srivastava et al. 2007; Mishra et al. 2008). Moreover, Myriophyllum propinquum (A. Cunn) is shown to be a strong As accumulator $\left(>2 \mathrm{~g} \mathrm{~kg}^{-1}\right)$ after a field survey of lakes and rivers containing elevated levels of As in the Taupo volcanic zone, New Zealand (Robinson et al. 2006). However, that accumulation may be primarily a consequence of surface adsorption of arsenate, facilitated by co-deposition with other adsorptive species such as hydrated Fe oxides, rather than a direct uptake into plant cells.

C. demersum L. (family Ceratophyllaceae), a worldwidedistributed submerged macrophyte, has been established to accumulate more than $1,000 \mu \mathrm{g} \mathrm{As} \mathrm{g}{ }^{-1}$ dry weight (DW) (Robinson et al. 2006). This plant is considered to be suitable for As phytofiltration because it is effective in capturing As from water and grows rapidly (Moreno-Jiménez et al. 2012). Besides, its rootless physiological feature and no translocation barrier from roots to shoots make it very different from terrestrial plants and an interesting model for investigating As metabolism in submerged macrophytes. However, the mechanisms of As uptake, accumulation, and efflux in this plant have not been elucidated. Thus, the main objectives of the present study were: (1) to determine the kinetics of arsenate and arsenite uptake, (2) to investigate As accumulation and transformation in $C$. demersum after exposure to arsenate and arsenite, and (3) to explore the possible influx and efflux mechanisms of As.

\section{Materials and methods}

\subsection{Plant growth}

C. demersum were obtained from Taihu Lake, Wuxi City, China, and were grown for 1 month in the pond of a greenhouse. Before the experiment, the plants (the tip portion of the shoot about $3 \mathrm{~cm}$ ) were grown in fresh water solution for 7 days. The composition of the synthetic fresh water was: $22.7 \mathrm{mg} \mathrm{L}^{-1} \mathrm{MgSO}_{4} \cdot 7 \mathrm{H}_{2} \mathrm{O}, 30.7 \mathrm{mg} \mathrm{L}{ }^{-1} \mathrm{MgCl}_{2} \cdot 2 \mathrm{H}_{2} \mathrm{O}$, $20.4 \mathrm{mg} \mathrm{L}^{-1} \mathrm{CaCl}_{2} \cdot 2 \mathrm{H}_{2} \mathrm{O}, 45.7 \mathrm{mg} \mathrm{L}^{-1} \mathrm{NaCl}, 26.0 \mathrm{mg} \mathrm{L}^{-1}$ $\mathrm{NaHCO}_{3}, 3.61 \mathrm{mg} \mathrm{L}{ }^{-1} \mathrm{KCl}, 1.41 \mathrm{mg} \mathrm{L}{ }^{-1} \mathrm{FeCl}_{3} \cdot 6 \mathrm{H}_{2} \mathrm{O}$, $0.97 \mathrm{mg} \mathrm{L}^{-1} \mathrm{Al}_{2}\left(\mathrm{SO}_{4}\right)_{3} \cdot 18 \mathrm{H}_{2} \mathrm{O}, 0.19 \mathrm{mg} \mathrm{L}^{-1} \mathrm{MnCl}_{2} \cdot 4 \mathrm{H}_{2} \mathrm{O}$, $3.86 \mu \mathrm{g} \mathrm{L}^{-1} \mathrm{ZnSO}_{4} \cdot 7 \mathrm{H}_{2} \mathrm{O}, 2.17 \mu \mathrm{g} \mathrm{L}^{-1} \mathrm{CuCl}_{2} \cdot 2 \mathrm{H}_{2} \mathrm{O}(\mathrm{pH}$ adjusted to 7.0 with $\mathrm{NaOH}$ or $\mathrm{HCl}$ solutions) (Stauber and Florence 1989). Plants were acclimatized inside a controlled environment growth cabinet under the following conditions: $115 \mu \mathrm{mol} \mathrm{m}{ }^{-2} \mathrm{~s}^{-1}$ light with a 14 -h photoperiod at $25 \pm 2{ }^{\circ} \mathrm{C}$.

\subsection{Kinetics of arsenic uptake}

After being pre-cultured for 1 week, $C$. demersum were washed with de-ionized water and blotted dry. Plant shoots (about $0.3 \mathrm{~g}$ ) were incubated in conical flasks $(150 \mathrm{~mL})$ containing 5.0 mM MES (2-( $N$-morpholino) ethanesulfonic acid hydrate) and $0.5 \mathrm{mM} \mathrm{CaCl}_{2}(\mathrm{pH} 6.0)$, with different concentrations $(0,20,40,80$, and $160 \mu \mathrm{M})$ of arsenate $\left(\mathrm{Na}_{3} \mathrm{~A}-\right.$ $\left.\mathrm{sO}_{4} \cdot 12 \mathrm{H}_{2} \mathrm{O}\right)$ and arsenite $\left(\mathrm{NaAsO}_{2}\right)$. Experiments were set up in triplicate at each As concentration. The flasks were shaken at $60 \mathrm{rpm}$ for $20 \mathrm{~min}$, then plants were collected and rinsed in an ice-cold phosphate solution $\left(1 \mathrm{mM} \mathrm{K}_{2} \mathrm{HPO}_{4}\right.$, $5 \mathrm{mM} \mathrm{MES}$, and $0.5 \mathrm{mM} \mathrm{CaCl}_{2}, \mathrm{pH} \mathrm{6.0)}$ for $10 \mathrm{~min}$ to remove the adsorbed As from the shoot-free space (Abedin et al. 2002). After desorption, plants were blotted dry and ovendried to constant weight at $70{ }^{\circ} \mathrm{C}$. Subsamples were digested by microwave, and As concentrations were determined.

\subsection{Arsenic accumulation and speciation}

C. demersum (1-g shoots of plants in each container) were transferred to vessels $(10 \mathrm{~cm}$ in diameter and $10 \mathrm{~cm}$ in depth) containing $500 \mathrm{~mL}$ freshwater with different concentrations of arsenate or arsenite $(0,1.25,5,10,20,40 \mu \mathrm{M})$, 
each with three replicates. After exposure at $10 \mu \mathrm{M}$ arsenate or arsenite for 1 and 4 days, $1 \mathrm{~mL}$ solution was taken from each pot, diluted with phosphate buffer solution (PBS) containing $2 \mathrm{mM} \mathrm{NaH}_{2} \mathrm{PO}_{4}$ and $0.2 \mathrm{mM} \mathrm{Na}_{2}$-EDTA (pH 6.0), which can effectively prevent arsenite oxidation (Xu et al. 2007), and kept on ice before analysis of As speciation. Plants were harvested after 4 days of exposure and immersed for $10 \mathrm{~min}$ in an ice-cold desorption solution as described before to remove apoplastic As (Abedin et al. 2002). Half of the plant samples were blotted dry and ground in a mortar and pestle with liquid $\mathrm{N}_{2}$ to fine powder. Subsamples (0.3-0.5 g) of the ground materials were extracted with $10 \mathrm{~mL}$ PBS solution for $1 \mathrm{~h}$ under sonication at $4{ }^{\circ} \mathrm{C}$. The extract was filtered through $0.45-\mu \mathrm{m}$ filters before analysis of As speciation (Xu et al. 2007), while the other half of the plant samples were oven-dried and used to determine the total As concentrations (see Section 2.7).

\subsection{Effect of microorganisms on arsenic transformation}

In order to test the effects of microbes living in solution or exudates of $C$. demersum on transformation of As, the solution used to cultivate $C$. demersum for 4 days was collected and divided into two portions according to the method reported by $\mathrm{Xu}$ et al. (2007). A portion was unfiltered (solution B) and another filtered through a sterilized $0.2-\mu \mathrm{m}$ filter into a sanitized vial to remove microorganisms living in the solution (solution $\mathrm{C}$ ). The freshwater solution that had not been used for growing plants was used as a control (solution A). Arsenate or arsenite $(10 \mu \mathrm{M})$ was added to the three solutions, followed by incubation in darkness for 1 day inside the same incubator as used for experiment 2.3. Each treatment was replicated threefold. Arsenic speciation was determined.

\subsection{Arsenic influx and efflux mechanisms}

This experiment was set up to examine if arsenate and arsenite are taken up via the $\mathrm{P}$ and aquaporin transporters, respectively, in $C$. demersum, as have been shown for other nonhyperaccumulator species. The effects of $\mathrm{P}\left(\mathrm{K}_{2} \mathrm{HPO}_{4} \cdot 3 \mathrm{H}_{2} \mathrm{O}\right)$; glycerol, which is transported by aquaporins; and an arsenite analog $\mathrm{Sb}\left(\mathrm{C}_{4} \mathrm{H}_{4} \mathrm{KO}_{7} \mathrm{Sb} \cdot 1 / 2 \mathrm{H}_{2} \mathrm{O}\right)$ on arsenic influx were investigated. Shoots of plants (about $0.3 \mathrm{~g}$ ) were subjected to four treatments: control $(20 \mu \mathrm{M}$ arsenate or arsenite solutions containing 5.0 mM MES and $0.5 \mathrm{mM} \mathrm{CaCl}_{2}, \mathrm{pH} 6.0$ ), + $100 \mu \mathrm{M}$ P, + $20 \mathrm{mM}$ glycerol, and $+0.5 \mathrm{mM} \mathrm{Sb}$. Each treatment was replicated threefold. Plants were harvested after $20 \mathrm{~min}$ of exposure and oven-dried to constant weight at $70^{\circ} \mathrm{C}$ after desorption of the apoplastic As. Arsenic concentrations of plant shoots were determined (see Section 2.7).

Additionally, in order to investigate whether the efflux of As by $C$. demersum takes the same transport pathway as the influx, the effects of three inhibitors on As efflux were determined: metabolic inhibitor carbonyl cyanide $m$-chlorophenylhydrazone (CCCP), P-type ATPase inhibitor sodium vanadate, and glycerol. After $24 \mathrm{~h}$ of treatment with $20 \mu \mathrm{M}$ arsenate, plants were desorbed of the apoplastic As as described before, then exposed to freshwater solutions $(50 \mathrm{~mL})$ with different treatments: control (freshwater), + $1 \mu \mathrm{M}$ CCCP, $+200 \mu \mathrm{M}$ sodium vanadate, and $+10 \mathrm{mM}$ glycerol. All the solutions were buffered at $\mathrm{pH} 6.0$ with $1 \mathrm{mM}$ MES. There were three replicates in each treatment. Solutions were sampled after $2 \mathrm{~h}$ of treatments, preserved in PBS, and stored on ice to determine As speciation.

\subsection{Analysis of arsenic speciation}

Arsenic speciation in solutions and plant extracts was determined by high performance liquid chromatographyinductively coupled plasma-mass spectrometry (HPLC-ICPMS) (Agilent LC1100 series and Agilent ICP-MS 7500a; Agilent Technologies) as reported by Zhang et al. (2009). Arsenic species (arsenite, arsenate, dimethylarsinic acid, and monomethylarsonic acid) were separated by an anionexchange column (Hamilton PRP-X100) with a mobile phase of $7.5 \mathrm{mM}$ ammonium di-hydrogen phosphate and $7.5 \mathrm{mM}$ ammonium nitrate ( $\mathrm{pH}$ 6.2). Arsenic species in the samples were identified by comparisons with the retention times of standard compounds and quantified by external calibration curves with peak areas. For each batch of samples, the analysis was completed within $12 \mathrm{~h}$ of collection; no changes in As speciation were observed during this period. The recovery for the sum of the As species compared to the total As concentrations in plant tissue was about $60 \%$.

\subsection{Digestion and analysis of total As}

For the estimation of total As, samples were prepared and analyzed according to that reported by Zhang et al. (2009). Dried plant shoots $(0.02 \mathrm{~g})$ were digested in $5 \mathrm{~mL}$ of highpurity nitric acid overnight and heated in a microwaveaccelerated reaction system (CEM Microwave Technology Ltd, USA). The temperature was raised gently (over a 5-min period), first to $55^{\circ} \mathrm{C}$ and then to $75{ }^{\circ} \mathrm{C}$ with holding times of $10 \mathrm{~min}$. Finally, the digest was taken up to $95^{\circ} \mathrm{C}$ for $30 \mathrm{~min}$. After cooling, the digests were diluted to $25 \mathrm{~mL}$ with Millipore ultrapure water. Arsenic concentration was determined by atomic fluorescence spectrometry (AF-610A, Beijing Haiguang Analytical Instrument Co., Beijing, China). Quality assurance of As analysis was included using a reagent blank and a standard reference material (bush twigs and leaves, GBW07602 from the National Research Center for Standard Materials in China) which was within $100 \pm 20 \%$ of the expected quality control checks. 


\subsection{Data analysis}

Data are analyzed by multivariate analysis of variance using windows based SPSS 13.0, followed by post hoc testing using ANOVA.

\section{Results}

\subsection{Uptake kinetics of arsenate and arsenite}

Both arsenate and arsenite uptake followed a hyperbolic pattern in relation to the external concentration (Fig. 1). Arsenic influx kinetics can be well described by the Michaelis-Menten equation with $R^{2}$ values of 0.986 and 0.998 for arsenate and arsenite, respectively (data not shown). From the fitted model, $V_{\max }$ for arsenate uptake $\left(214 \pm 13 \mathrm{nmol} \mathrm{g}{ }^{-1} \mathrm{DW} \mathrm{min}^{-1}\right)$ was almost two times of the arsenite uptake $\left(128 \pm 8 \mathrm{nmol} \mathrm{g}^{-1}\right.$ DW $\left.\min ^{-1}\right)$, whereas the $K_{\mathrm{m}}$ for arsenate uptake $(18 \pm 4.5 \mu \mathrm{M})$ was about one tenth of the arsenite uptake $(120 \pm 14 \mu \mathrm{M})$.

\subsection{Accumulation of As inorganic species}

In the control treatment, the concentration of As in the shoot of $C$. demersum was only $1.7 \mu \mathrm{g} \mathrm{g}^{-1} \mathrm{DW}$, indicating that the original plant was not contaminated by As. After 4 days of incubation, As accumulation was higher in plant shoots exposed to lower concentrations of arsenate compared to arsenite $(1.25$ and $5 \mu \mathrm{M})$. The accumulation of As increased significantly $(P<0.05)$ with increasing concentrations of As in external solutions until it reached maximums at $10 \mu \mathrm{M}$ As treatments, with arsenite accumulation $\left(963 \mu \mathrm{g} \mathrm{g}^{-1} \mathrm{DW}\right)$ markedly exceeding arsenate accumulation $\left(862 \mu \mathrm{g} \mathrm{g}^{-1}\right.$ DW) (Fig. 2). Then sharp decreases of As accumulation in

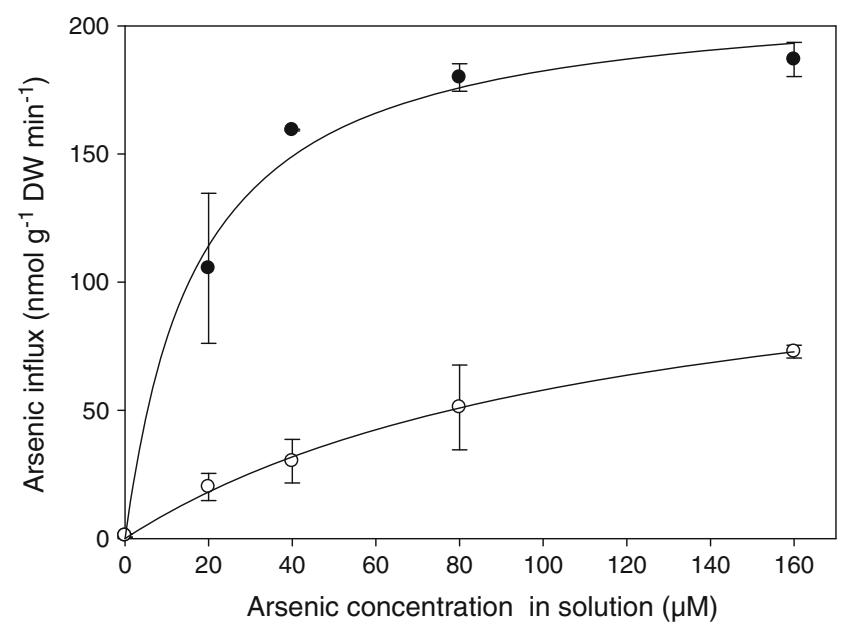

Fig. 1 Concentration-dependent kinetics for arsenate (closed circles) and arsenite (open circles) uptake by a shoot of $C$. demersum exposed to different concentrations of As for $20 \mathrm{~min}$. The graph shows Michaelis-Menten curves for each As species. Data are mean \pm SD $(n=3)$

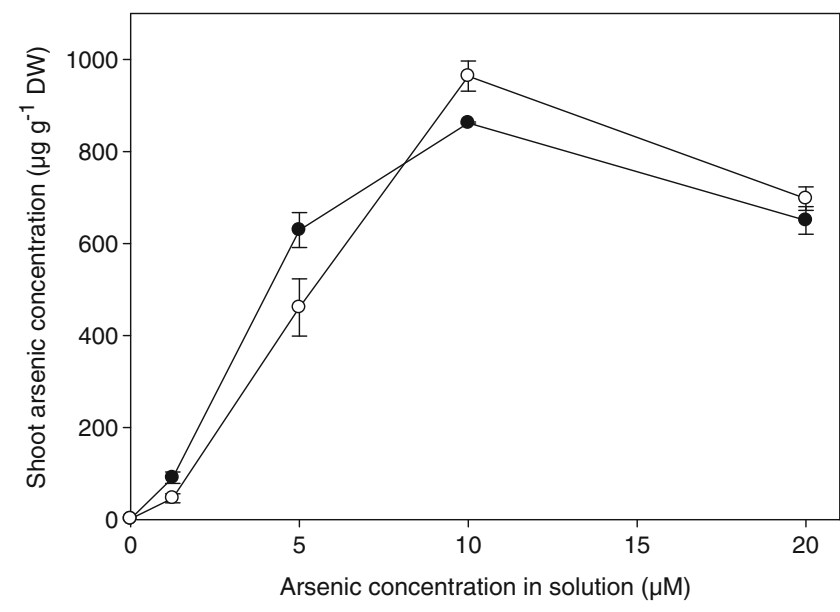

Fig. 2 Arsenic concentrations in shoots of $C$. demersum exposed to different concentrations of arsenate (closed circles) and arsenite (open circles) for 4 days. Data are mean $\pm \mathrm{SD}(n=3)$

plant shoots exposed to $20 \mu \mathrm{M}$ arsenate and arsenite were observed, probably due to the chlorosis of the leaf caused by As toxicity. Plants died after being exposed to $40 \mu \mathrm{M}$ As for 4 days, so data of these treatments were not shown in Figs. 2 and 3 .

\subsection{Arsenic speciation in C. demersum}

In the control plant, arsenite concentration was only $0.01 \mathrm{\mu g} \mathrm{g}^{-1}$ fresh weight (FW), about one third of the arsenate concentration $\left(0.03 \mu \mathrm{g} \mathrm{g}^{-1} \mathrm{FW}\right)$. Regardless of the As species supplied, arsenite was the dominant species of As in C. demersum, accounting for 76-94 and 89-98\% of the total extractable As in plants exposed to arsenate and arsenite, respectively (Fig. 3). Both arsenite and arsenate concentrations in plants increased with increasing solution concentration of As ranging from 1.25 to $10 \mu \mathrm{M}$, with no significant differences between different As speciation treatments $(P>0.05)$. Dramatic decreases of arsenite concentrations in plants were observed in the $20-\mu \mathrm{M}$ As treatments. No methylated As species were detected in the plants.

\subsection{Arsenic speciation in external solutions}

At days 1 and 4, arsenate concentrations in the solutions of the arsenate treatments decreased by 49.1 and $95.5 \%$, respectively. However, arsenite was observed in the solution, accounting for 84 and $67 \%$ of arsenate removal by plants at days 1 and 4, respectively. At the end of the experiment (4 days), $94 \%$ of the As remaining in the solution was present as arsenite (Fig. 4). By contrast, arsenite remained relatively stable in the freshwater solutions of the arsenite treatments and comprised about $97 \%$ of the As in the solution at both days 1 and 4. No methylated As species was found in the solutions (Fig. 4). 
Fig. 3 Speciation of As (arsenate, closed circles; arsenite, open circles) in a shoot of $C$. demersum after exposure to different arsenate (A) or arsenite (B) concentrations for 4 days. Data are mean $\pm \mathrm{SD}(n=3)$

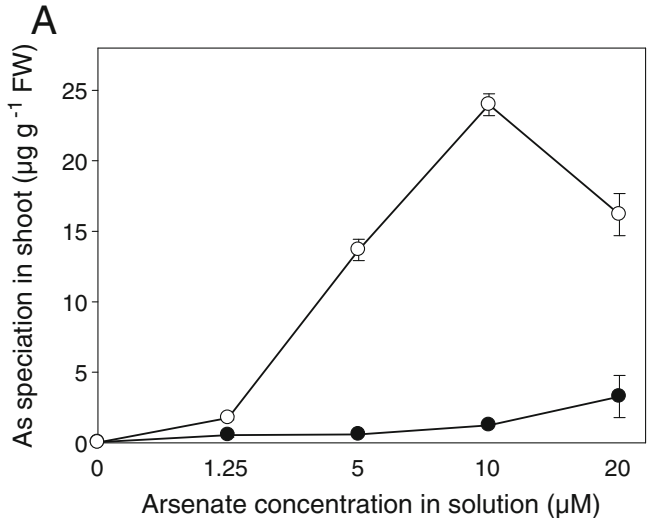

B

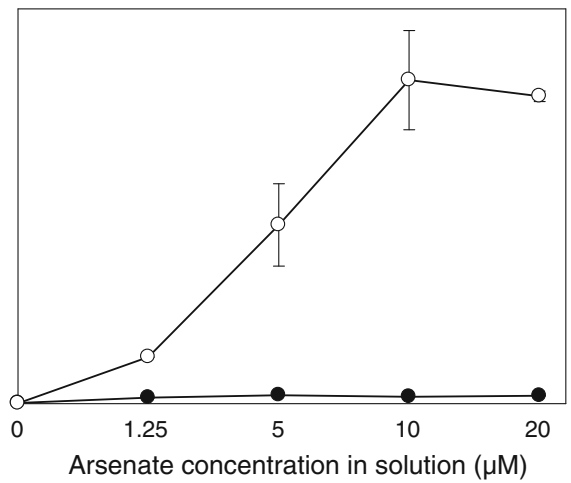

After $24 \mathrm{~h}$ of incubation, arsenite remained stable in all three solutions, occupying $99 \%$ of the initial concentration (Fig. 5). As for the arsenate treatments, there was only $0.83 \%$ of arsenite in solution A. About 11 and $6.0 \%$ of the arsenate were reduced to arsenite in solutions $\mathrm{B}$ and $\mathrm{C}$, respectively. It was far less than the extent of arsenate reduction observed in the freshwater solution growing the plant shoot (Figs. 4 and 5).

\subsection{Effects of inhibitors to influx and efflux of As}

In the control treatment, the influx of arsenate was about twice that of arsenite (Fig. 6). Arsenate transport was markedly inhibited by $\mathrm{P}$ but was unaffected by other inhibitors (glycerol and $\mathrm{Sb}$ ). Compared to the control treatment, arsenite uptake was unaffected in the presence of $\mathrm{P}$, whereas it was reduced by 85 and $44 \%$ in the presence of $20 \mathrm{mM}$ glycerol and $0.5 \mathrm{mM} \mathrm{Sb}$, respectively $(P<0.05)$.

Both arsenate and arsenite efflux to the external solution were observed, and the concentration of arsenite was about

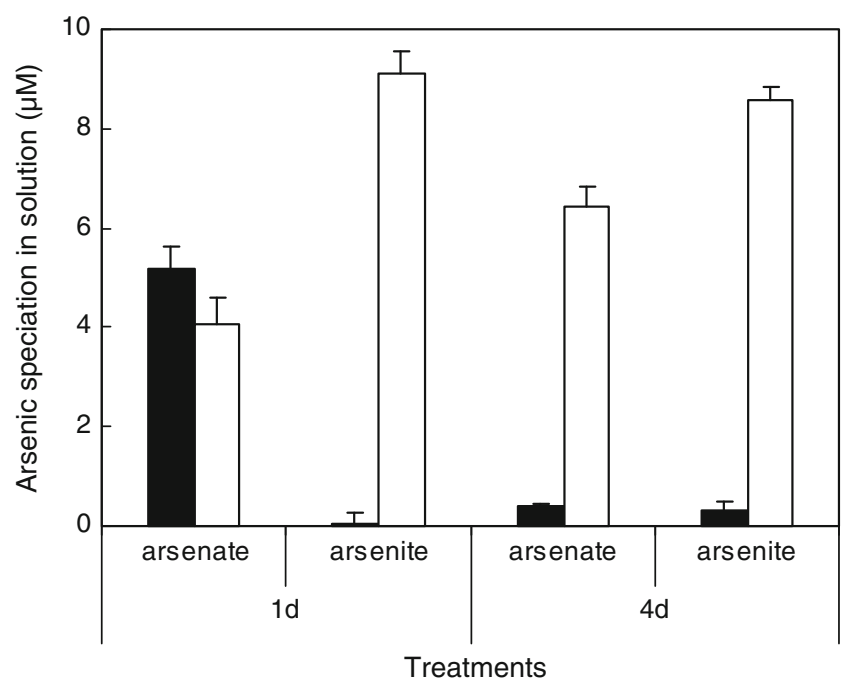

Fig. 4 Concentrations (mean $\pm \mathrm{SD}, n=3$ ) of arsenate (closed bars) and arsenite (open bars) in the synthetic freshwater solutions after $C$. demersum were supplied with $10 \mu \mathrm{M}$ arsenate and arsenite for 1 and 4 days twofold higher than that of arsenate in the control treatment (Fig. 7). Vanadate significantly enhanced arsenate efflux but exerted no effect on arsenite efflux $(P>0.05)$. In addition, CCCP and glycerol had no effect on arsenate efflux but markedly decreased about 65 and $49 \%$ arsenite efflux, respectively, compared to the control $(P>0.05)$.

\section{Discussion}

In the present study, a higher accumulation of As was observed in plant shoots exposed to arsenate compared to arsenite (1.25 and $5 \mu \mathrm{M}$ ) (Fig. 2). This could result from the higher influx rate of arsenate in contrast to that of arsenite in solutions without P (Fig. 1). Compared with other aquatic plants, such as Azolla caroliniana, Azolla filiculoides, and $W$. globosa, $C$. demersum has a much higher arsenate influx rate (about three- to tenfold) and a lower $K_{\mathrm{m}}$ (about half to one tenth), indicating the higher affinity of transporters for arsenate. For the arsenite influx, the $V_{\max }$ and $K_{\mathrm{m}}$ values

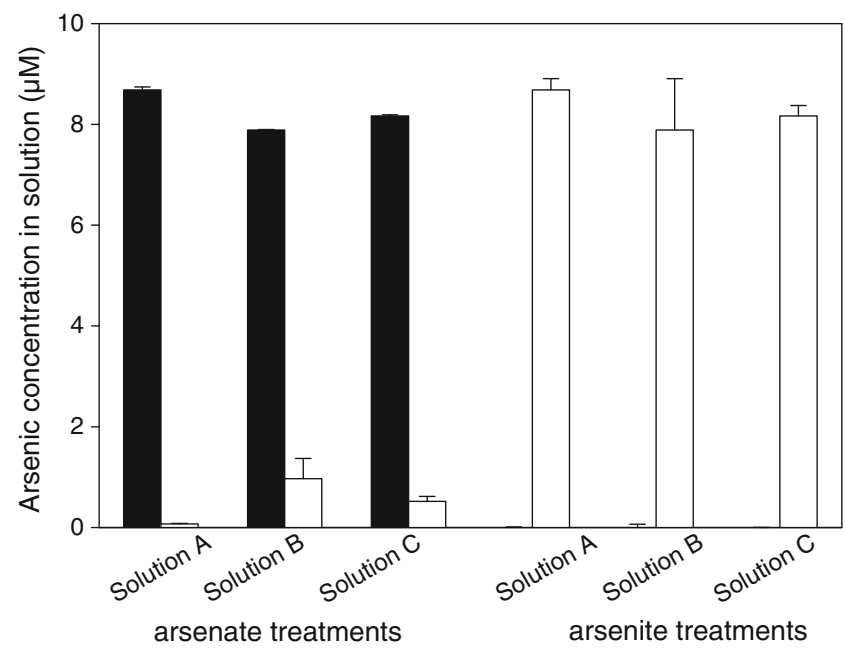

Fig. 5 Transformation of arsenate (closed bars) and arsenite (open bars) in freshwater solutions with three different treatments: solution A (control that had not been used to grow plants), solution B (had been used to grow $C$. demersum for 4 days), and solution $\mathrm{C}$ (solution B after being further sterilized). Data are mean $\pm \mathrm{SD}(n=3)$ 


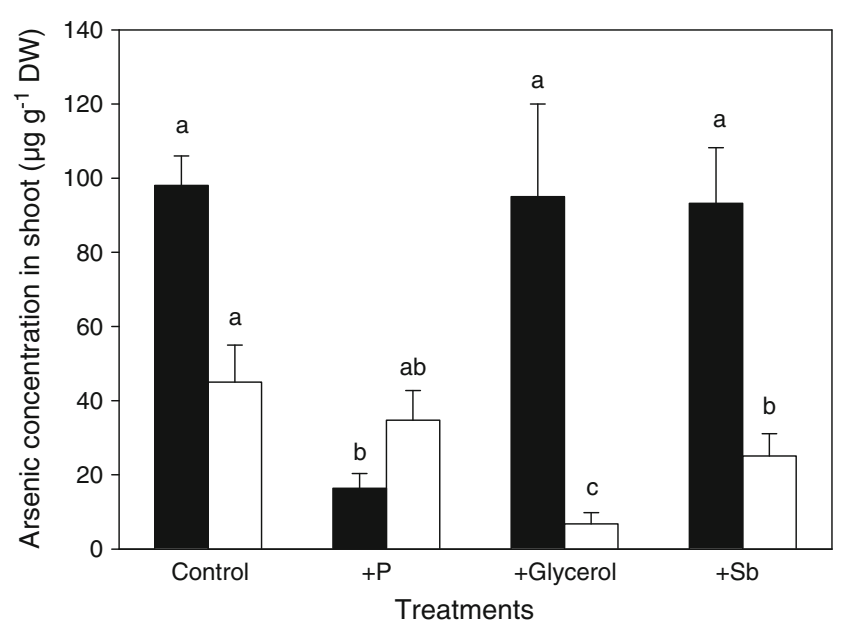

Fig. 6 Inhibition of arsenate (closed bars) and arsenite uptake (open bars) by $\mathrm{P}(100 \mu \mathrm{M})$, glycerol $(20 \mathrm{mM})$, and $\mathrm{Sb}(0.5 \mathrm{mM})$. Plants were exposed to $20 \mu \mathrm{M}$ arsenate and arsenite solutions with different treatments for $20 \mathrm{~min}$. Data are mean \pm SD $(n=3)$. Different letters indicate significant difference between treatments for arsenate and arsenite influx $(P<0.05)$

were comparable to those for $W$. globosa (Zhang et al. 2008, 2009). However, a maximum accumulation of As (963 $\left.\mu \mathrm{g} \mathrm{g}^{-1} \mathrm{DW}\right)$ in plants exposed to $10 \mu \mathrm{M}$ arsenite after 4 days was higher than that $\left(862 \mu \mathrm{g} \mathrm{g}^{-1} \mathrm{DW}\right)$ in plants exposed to $10 \mu \mathrm{M}$ arsenate $(P<0.05)$ (Fig. 2). In the $20-\mu \mathrm{M}$ As treatment, the dramatic drop of total As and arsenite concentrations in plants possibly indicated a decrease of arsenate reduction capacity caused by As toxicity, with the chlorosis of the leaves being observed. These findings also clearly indicated $C$. demersum as a strong accumulator of

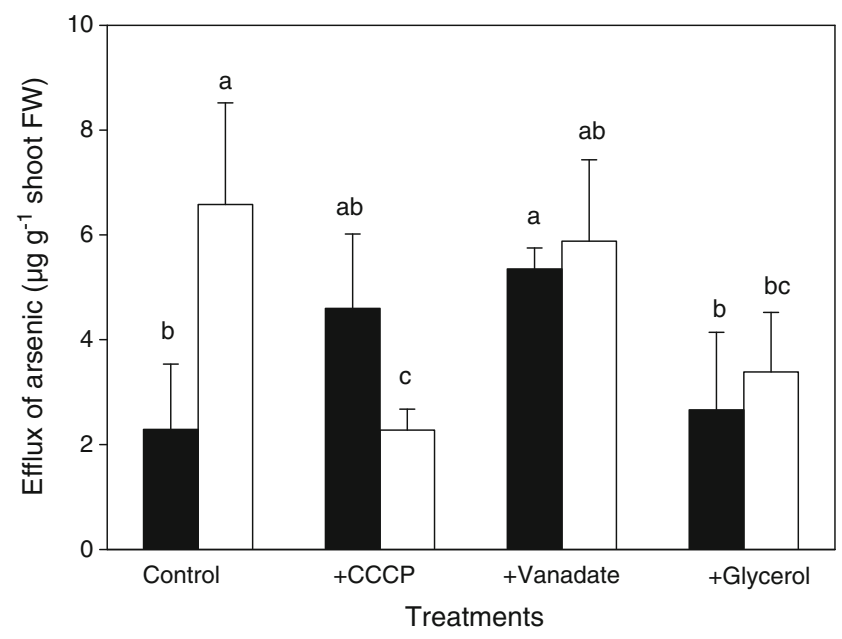

Fig. 7 Effects of CCCP $(1 \mu \mathrm{M})$, sodium vanadate $(200 \mu \mathrm{M})$, and glycerol $(10 \mathrm{mM})$ on the efflux of arsenate (closed bars) and arsenite (open bars) from plant shoots to external solutions. Plants were incubated in $20 \mu \mathrm{M}$ arsenate solution for $24 \mathrm{~h}$ before being used in the efflux experiment. Results are normalized by shoot FW. Data are mean \pm SD $(n=3)$. Different letters indicate significant difference between treatments for arsenate and arsenite efflux $(P<0.05)$
As. It accumulated As in 4 days, twice more than other aquatic plants in $\geq 7$ days, such as Azolla, $H$. verticillata, and $M$. propinquum, all of which accumulated $<400 \mu \mathrm{g} \mathrm{As} \mathrm{g}^{-1} \mathrm{DW}$ after exposure to $>20-\mu \mathrm{M}$ arsenate solutions (Robinson et al. 2006; Srivastava et al. 2007; Zhang et al. 2008). Its accumulation of As was similar to that of $W$. globosa, which has recently been reported as a strong accumulator of As $(1,057$ and $1,070 \mu \mathrm{g} \mathrm{As} \mathrm{g}^{-1} \mathrm{DW}$ accumulated after 7 days of exposure to $15 \mu \mathrm{M}$ arsenite and $30 \mu \mathrm{M}$ arsenate, respectively). The authors attributed the strong As accumulation to the absence of roots and direct uptake by shoots (Zhang et al. 2009), which could also apply to C. demersum. However, according to that reported by Mishra et al. (2008), C. demersum only accumulated $525 \mathrm{mg} \mathrm{As} \mathrm{kg}{ }^{-1}$ after being grown for 7 days in $250 \mu \mathrm{M}$ arsenate, which may have been due to the competition of arsenate with $\mathrm{P}$ $\left(9.6 \mathrm{mg} \mathrm{L}^{-1}\right)$ in their nutrient solution. This speculation can be supported by the fact that arsenate uptake by $C$. demersum was considerably inhibited by $\mathrm{P}$ in this study (Fig. 6), which confirmed that arsenate shares the P pathway to plant cells. Like arsenite $(p \mathrm{Ka}=9.2), \mathrm{Sb}(p \mathrm{Ka}=11.8)$ exists predominantly as an undissociated neutral molecule at $\mathrm{pH} 6.0$, and it can be transported via aquaporins in some plants (Zhao et al. 2009). The competition of arsenite uptake by $\mathrm{Sb}$ and glycerol in C. demersum (Fig. 6) may indicate that arsenite is transported across the plasma membrane via major intrinsic proteins/aquaporins as found in Saccharomyces cerevisiae and rice (Wysocki et al. 2001; Meharg and Jardine 2003).

Different from the study by Zheng et al. (2003) on $C$. demersum, no matter what arsenic species are initially supplied to the plants, most of the As (>86\%) in plant shoots was in the form of arsenite rather than arsenate (Fig. 3). The possible explanations were that plant samples obtained by Zheng et al. (2003) were air-dried before As speciation analysis, which may cause oxidation of arsenite as it is thermodynamically unstable in oxygenated environments. Further, the extraction efficiency of the methanol-water method used in their study was very low (6.3-16.1\%). Whereas, in this study, plants were preserved in liquid $\mathrm{N}_{2}$ after sampling and extracted by PBS solution with EDTA in it to prevent arsenite oxidation (Bednar et al. 2002), followed by immediate analysis of As speciation using HPLC-ICP-MS. Also, the extraction rate was much higher (about $60 \%$ ) in our study. The same phenomenon in which arsenite was the dominant species of As in $C$. demersum when supplied with inorganic As was also observed in other higher plants, such as rice (Oryza sativa), tomato (Lycopersicon esculentum), A. caroliniana, A. filiculoides, and $W$. globosa, which were also preserved in liquid $\mathrm{N}_{2}$ before analysis of As speciation with immediate testing using HPLC-ICP-MS after extraction (Xu et al. 2007; Zhang et al. 2008, 2009). 
Arsenate added to the solution was rapidly converted to arsenite (Fig. 4). More than $60 \%$ of arsenate taken up by plants was reduced to arsenite and leaked to external solutions after 4 days of exposure. It can be concluded that microbes living in the synthetic solution or shoot exudates contributed little to arsenate reduction (Fig. 5). All these indicated that arsenite in solution is extruded by the plant shoot following arsenate reduction inside the shoot cells. This can also be supported by the fact that most of the As in shoots of plants was in the form of arsenite (Fig. 3). Arsenite efflux has also been observed in other plant species (non-hyperaccumulators), including W. globosa, Azolla, Arabidopsis thaliana, Holcus lanatus, rice, tomato, wheat (Triticum aestivum), barley (Hordeum vulgare), and maize (Zea mays), but not in the As hyperaccumulator Pteris vittata (Xu et al. 2007; Zhang et al. 2008, 2009; Logoteta et al. 2009; Zhao et al. 2009). Accordingly, arsenate reduction followed by arsenite efflux is probably a general phenomenon in higher plants except in hyperaccumulators and may act as an important mechanism of As detoxification as has been shown for microbes (Bhattacharjee and Rosen 2007).

Clear evidence for efflux of both arsenite and arsenate from shoots of $C$. demersum was shown (Figs. 4 and 7), with arsenite efflux being higher than arsenate efflux under freshwater solutions for $2 \mathrm{~h}$. Furthermore, coinciding with the study on tomato root (Xu et al. 2007), arsenite efflux was not affected by vanadate but markedly suppressed by CCCP (66\%) (Fig. 7), suggesting that the efflux is not mediated by a P-type ATPase, but relies on the proton gradient across the plasma membranes for energy. Interestingly, due to the dramatic inhibition of arsenite efflux by glycerol which had no effect on arsenate efflux (Fig. 7), it can be postulated that the efflux of arsenite from plant shoots through aquaporin channels is like arsenite influx, some of which allow bidirectional passage of solutes (Mitani et al. 2008). Also, the fast efflux of arsenite (Figs. 4 and 7) is consistent with an aquaporin-mediated efflux which occurs through diffusion when the internal arsenite concentration exceeds that in the external medium. As a result, arsenite can be extruded from the plant shoot both through passive diffusion and active transport. Moreover, greatly enhanced efflux of arsenate by vanadate may indicate this to be a passive process as suggested in tomato roots (Xu et al. 2007). Because the uptake of arsenate through $\mathrm{P}$ transporters probably needs P-type ATPase, diminished ATPase would be expected to decrease arsenate uptake and to increase the release of arsenate to the external solutions, especially when shoots were placed in a solution without As.

In conclusion, owing to the substantial capacity of $C$. demersum for As accumulation, this plant appears to have potential for remediating As moderately contaminated waters. But the rapid leakage of arsenite into the external solution after the reduction of arsenate may limit its application in As phytofiltration. Furthermore, C. demersum is considered as an invasive species, therefore, its use in phytofiltration should be conducted very carefully. However, $C$. demersum can serve as an ideal model plant to study As uptake and metabolism in a submerged macrophyte due to its special morphology without roots.

Acknowledgments The authors are grateful to Prof. Yong-Guan Zhu (Institute of Urban Environment, Chinese Academy of Sciences) for his technical support. This study was financially supported by the National Natural Science Funds of China (grant no. 20777059) and the Key Program of Science and Technology, Fujian Province (grant no. 2010Y0055).

\section{References}

Abedin MJ, Feldmann J, Meharg AA (2002) Uptake kinetics of arsenic species in rice plants. Plant Physiol 128:1120-1128

Bednar AJ, Garbarino JR, Ranville JF, Wildeman TR (2002) Preserving the distribution of inorganic arsenic species in groundwater and acid mine drainage samples. Environ Sci Technol 36:2213-2218

Bhattacharjee Y (2007) Toxicology—a sluggish response to humanity's biggest mass poisoning. Science 315:1659-1661

Bhattacharjee H, Rosen BP (2007) Arsenic metabolism in prokaryotic and eukaryotic microbes. In: Nies DH, Silver S (eds) Molecular microbiology of heavy metals. Springer, Berlin, pp 371-406

Jackson LJ (1998) Paradigms of metal accumulation in rooted aquatic vascular plants. Sci Total Environ 219:223-231

Logoteta B, Xu XY, Macnair MR, McGrath SP, Zhao FJ (2009) Arsenite efflux is not enhanced in the arsenate-tolerant phenotype of Holcus lanatus. New Phytol 183:340-348

Ma LQ, Komar KM, Tu C, Zhang WH, Cai Y, Kennelley ED (2001) A fern that hyperaccumulates arsenic - a hardy, versatile, fastgrowing plant helps to remove arsenic from contaminated soils. Nature 409:579-579

Meharg AA, Hartley-Whitaker J (2002) Arsenic uptake and metabolism in arsenic resistant and nonresistant plant species. New Phytol 154:29-43

Meharg AA, Jardine L (2003) Arsenite transport into paddy rice (Oryza sativa) roots. New Phytol 157:39-44

Mishra S, Srivastava S, Tripathi RD, Trivedi PK (2008) Thiol metabolism and antioxidant systems complement each other during arsenate detoxification in Ceratophyllum demersum L. Aquat Toxicol 86:205-215

Mitani N, Yamaji N, Ma JF (2008) Characterization of substrate specificity of a rice silicon transporter, Lsi1. Pflug Arch Eur J Phys 456:679-686

Moreno-Jiménez E, Esteban E, Peñalosa JM (2012) The fate of arsenic in soil-plant systems. Rev Environ Contam Toxicol 215:1-37. doi:10.1007/978-1-4614-1463-6 1

Robinson B, Kim N, Marchetti M, Moni C, Schroeter L, van den Dijssel C, Milne G, Clothier B (2006) Arsenic hyperaccumulation by aquatic macrophytes in the Taupo Volcanic Zone, New Zealand. Environ Exp Bot 58:206-215

Smedley PL, Kinniburgh DG (2002) A review of the source, behaviour and distribution of arsenic in natural waters. Appl Geochem 17:517-568

Srivastava S, Mishra S, Tripathi RD, Dwivedi S, Trivedi PK, Tandon PK (2007) Phytochelatins and antioxidant systems respond differentially during arsenite and arsenate stress in Hydrilla verticillata (L.f) Royle. Environ Sci Technol 41:2930-2936 
Stauber JL, Florence TM (1989) The effect of culture medium on metal toxicity to the marine datom Nitzschia closterium and the fresh water green alga Chlorella pyrenoidosa. Water Res 23:907-911

Tripathi RD, Srivastava S, Mishra S, Singh N, Tuli R, Gupta DK, Maathuis FJM (2007) Arsenic hazards: strategies for tolerance and remediation by plants. Trends Biotechnol 25:158-165

Wysocki R, Chery CC, Wawrzycka D, Van Hulle M, Cornelis R, Thevelein JM, Tamas MJ (2001) The glycerol channel Fps1p mediates the uptake of arsenite and antimonite in Saccharomyces cerevisiae. Mol Microbiol 40:1391-1401

Xu XY, McGrath SP, Zhao FJ (2007) Rapid reduction of arsenate in the medium mediated by plant roots. New Phytol 176:590-599

Zhang X, Lin AJ, Zhao FJ, Xu GZ, Duan GL, Zhu YG (2008) Arsenic accumulation by the aquatic fern Azolla: comparison of arsenate uptake, speciation and efflux by $A$. caroliniana and $A$. filiculoides. Environ Pollut 156:1149-1155

Zhang X, Zhao FJ, Huang Q, Williams PN, Sun GX, Zhu YG (2009) Arsenic uptake and speciation in the rootless duckweed Wolffia globosa. New Phytol 182:421-428
Zhao FJ, Dunham SJ, McGrath SP (2002) Arsenic hyperaccumulation by different fern species. New Phytol 156:27-31

Zhao FJ, Ma JF, Meharg AA, McGrath SP (2009) Arsenic uptake and metabolism in plants. New Phytol 181:777-794

Zhao FJ, McGrath SP, Meharg AA (2010) Arsenic as a food chain contaminant: mechanisms of plant uptake and metabolism and mitigation strategies. Annu Rev Plant Biol 61:535-559

Zheng J, Hintelmann H, Dimock B, Dzurko MS (2003) Speciation of arsenic in water, sediment, and plants of the Moira watershed, Canada, using HPLC coupled to high resolution ICP-MS. Anal Bioanal Chem 377:14-24

Zhu YG, Rosen BP (2009) Perspectives for genetic engineering for the phytoremediation of arsenic-contaminated environments: from imagination to reality? Curr Opin Biotech 20:220-224

Zhu YG, Sun GX, Lei M, Teng M, Liu YX, Chen NC, Wang LH, Carey AM, Deacon C, Raab A, Meharg AA, Williams PN (2008) High percentage inorganic arsenic content of mining impacted and nonimpacted Chinese rice. Environ Sci Technol 42:50085013 